\title{
Изучение топологии ростковых трубок бурой ржавчины на поверхности листа пшеницы на основе анализа конфокальных 3D-изображений
}

Зубаирова У.С. ${ }^{1 *}$, к.б.н., н.с.; Букатич Е.Ю. ${ }^{1}$, м.н.с.; Дорошков А.В. ${ }^{1}$, к.б.н., н.с.; Маловичко Е.С. ${ }^{2}$, студент; Орлова Е.А. ${ }^{3}$, к.с-х.н., в.н.с.; Афонников Д.А. ${ }^{l}$, к.б.н., B.H.C.

${ }^{1}$ ИЦиГ СО РАН, Новосибирск, Россия;

${ }^{2}$ НГУ, Новосибирск, Россия;

${ }^{3}$ СибНИИРС - филиал ИЦиГ СО РАН, Новосибирск, Россия.

*e-mail: ulyanochka@boinet.nsc.ru

Для изучения геометрии ростковых трубок бурой ржавчины (Риссіпіа recondita) на поверхности листа пшениць применен оригинальный подход, основанный на получении и обработке конфокальных $3 D$ изображений зараженных листьев, окрашенных флуоресцентными красителями. В работе проанализирован ряд 3D-изображений для шести сортов мягкой пшеницы и составлено иџфровое описание расположения ростковой трубки на поверхности листа.

Ключевые слова: бурая ржавчина, мягкая пшеница, конфокальная микроскопия, анализ изображений.

\section{Studying the topology of brown rust germination tubes on the wheat leaf surface based on confocal 3d-images analysis}

Zubairova U.S., Institute of cytology and genetics SB RAS, Novosibirsk, Russia, ulyanochka@boinet.nsc.ru;_Bukatich E.Yu., Institute of cytology and genetics SB RAS, Novosibirsk, Russia; Doroshkov A.V., Institute of cytology and genetics SB RAS, Novosibirsk, Russia; Malovichko E.S., Novosibirsk state university, Novosibirsk, Russia; Orlova E.A., Institute of cytology and genetics SB RAS, Novosibirsk, Russia; Afonnikov D.A., Institute of cytology and genetics SB RAS, Novosibirsk, Russia.

To study the topology of germinatin tubes of brown rust (Puccinia recondita) on the surface of a wheat leaf, an original approach based on the receipt and processing of confocal $3 D$ images of infected leaves stained with fluorescent dyes was used. We analyzed a number of $3 D$ images for six varieties of bread wheat and compiled a digital description of the location of the germination tube on the leaf surface.

Key words: brown rust, bread wheat, confocal microscopy, image analysis. 
Бурая ржавчина (Puccinia recondita) поражает листья пшеницы, в результате уменьшается их способность к фотосинтезу, что приводит к снижению урожайности пшеницы. Для изучения патогенеза этого заболевания используется широкий класс методов системной биологии, в том числе и компьютерные модели [1], которые рассматривают взаимодействие патогенрастение как комплексный процесс. Для изучения механизмов патогенеза ржавчинных заболеваний растений используется анализ изображений листьев зараженных зерновых культур, полученных методом конфокальной лазерной сканирующей микроскопии [2].

Для изучения геометрии ростковых трубок бурой ржавчины на поверхности листа пшеницы применен оригинальный подход, основанный на получении и обработке конфокальных 3D изображений зараженных листьев, окрашенных флуоресцентными красителями. Области листа, в которых ожидалось проявление болезни, фиксировались в 4 \% растворе параформальдегида в течение 3 или более часов и затем окрашивались красителями DAPI (SIGMA), Calcofluor White (SIGMA) и Propidium Iodide (SIGMA). Этот набор красителей на фиксированном материале обеспечивает достаточно устойчивую к выгоранию окраску ядер и клеточных стенок для клеток гриба и растения. Полученные препараты затем были отсканированы при помощи микроскопа ZEISS LSM 780 NLO в режиме многокадрового сканирования. Подбор области сканирования проводился исходя из необходимости обеспечить видимость всех клеточных стенок растения и границ ростковых трубок гриба. Обработка и анализ 3D-изображений проводилась с помощью разработанного авторами программного модуля для плагина LSM-W ${ }^{2}$ [3], позволяющего обрабатывать и анализировать конфокальные изображения бурой ржавчины на листьях пшеницы. Основными этапами алгоритма являются: (1) получение информации о градиенте поверхности листа, (2) получении серии изображений: (i) клеточной структуры эпидермиса листа, (ii) поверхности листа с ростковой трубкой, (iii) разметки-сегментации клеточной структуры, (iv) разметки-сегментации морфологических структур гриба (споры, ростковой трубки, аппрессория), (3) сопоставление полученных изображений с целью автоматического извлечения информации о расположении ростковой трубки на поверхности листа.

С помощью разработанного программного модуля проанализирован ряд 3D-изображений для шести сортов мягкой пшеницы и составлено цифровое описание расположения ростковой трубки на поверхности листа.

Благодарности: Исследование выполнено при финансовой поддержке РФФИ в рамках научного проекта № 17-29-08028. В работе использовались вычислительные ресурсы ЦКП «Биоинформатика» при поддержке бюджетного проекта № 0324-2019-0040-С-01. 


\section{Список литературы}

1. Nikolaev S.V., Zubairova U.S., Skolotneva E.S., Orlova E.A., Afonnikov D.A. A system approach to the modeling of fungal infections of the wheat leaf. Vavilovskii Zhurnal Genetiki i Selektsii=Vavilov Journal of Genetics and Breeding. 2019;23(1):100-109. DOI 10.18699/VJ19.468 (in Russian)

2. Solanki, S., Ameen, G., Borowicz, P., Brueggeman, R.S. (2019). Shedding light on penetration of cereal host stomata by wheat stem rust using improved methodology. Scientific reports, 9(1), 1-13.

3. Zubairova, U.S., Verman, P.Y., Oshchepkova, P.A., Elsukova, A.S., Doroshkov, A.V. (2019). LSM-W 2: laser scanning microscopy worker for wheat leaf surface morphology. BMC systems biology, 13 (1), 22.

\section{Влияние предпосевной обработки семян микроэлементами на урожайность сорта сои Жансая в условиях Алматинской области}

Кабылбекова Г.К. *, докторант; Дидоренко С.В., к.б.н., зав. отделом зернобобовых культур; Кудайбергенов М.С., д.б.н., г.н.с. отдела зернобобовых культур; Байтаракова К.Ж., с.н.с. отдела зернобобовых культур.

ТОО «Казахский научно-исследовательский институт земледелия и растениеводства», Алматы, Казахстан

*e-mail: shaiza_68@mail.ru

Изучено влияние предпосевной обработки семян сои растворами микроэлементов Мо и Со. Самое большое отклонение от контроля дала совместная обработка семян азотфиксирующими бактериями и микроэлементами $-8,4$ uุ/2a.

Ключевые слова: соя, микроэлементы, признаки продуктивности, урожайность.

\section{Effect of pre-seeding treatment of seeds with microelements on the yield of the soybaen variety in the conditions of the Almaty region}

Kabylbekova G.K., $2^{\text {nd }}$ year doctoral student shaiza 68@mail.ru, Didorenko S.V., candidate of biological sciences, head of the department of leguminous crop, Kudaibergenov M.S., Doctor of Biological Sciences, Chief Researcher at the Department of Leguminous Crops, Baitarakova K. Zh. - Senior Researcher at the Department of Pulses.

LLP "Kazakh Research Institute of Agriculture and Crop Production", Almaty, Kazakhstan.

The effect of pre-seeding treatment of soybean seeds with solutions of trace elements Mo and Co was studied. The largest deviation from the control was given 